EPJ Web of Conferences 33, 05008 (2012)

DOI: $10.1051 /$ epjconf $/ 20123305008$

(C) Owned by the authors, published by EDP Sciences, 2012

\title{
Upgrade opportunities for buildings in city centres
}

\author{
N. Brito ${ }^{1 \mathrm{a}}$, M. Silva ${ }^{2 \mathrm{~b}}$ \\ ${ }^{1}$ Universidade de Coimbra, Sustainable Energy Systems, Tv. de Montarroio, 2, 3000-288 Coimbra \\ ${ }^{2}$ Universidade de Coimbra, Sustainable Energy Systems, Departamento de Engenharia Mecânica
}

\begin{abstract}
This proposal focus on the potential of the existing buildings upgrade process in achieving the 20-20-20 goals, as these are the biggest energy consumers, the most significant built area and the better placed buildings within our cities.

These buildings frequently lack basic maintenance and need intervention, but include within themselves a vast amount of incorporated energy and centuries of construction knowledge. Beyond the advantages that may result from re-attracting people back into the city centre, upgrading these existing buildings can also have positive bounce-back effect on the reduction of the energy needs related to transportation, as demonstrated in studies that alert to the impact of the building sprawl in the total energy use.

As "buildings account for $40 \%$ of total energy consumption in the Union", the better performance of this sector has a significant role, remembering that "these requirements shall take account of general indoor climate conditions, in order to avoid possible negative effects such as inadequate ventilation, as well as local conditions and the designated function and the age of the building" [1].

The importance of "upgrading" the existing buildings resides on the fact that new buildings represent only approximately 1 or $2 \%$ of the total usable area, an estimate that is bound to decrease due to the current construction crisis. While the recent buildings tend to be more efficient, the numerous existing buildings are important stakeholders due to their massive consumptions and incorporated energy. The ongoing Annex 56 on "Energy \& Greenhouse Gas Optimized Building Renovation" assumes that "Current standards do not respond effectively to the numerous constraints imposed by existing buildings and in many cases, the requirements result in very expensive measures and complex procedures, seldom accepted by occupants, owners or developers. It is then urgent for the new standards to respond to these constraints and to develop good practice guides that integrate appropriate, applicable and cost effective technologies (existing or emergent ones)" [2].

Many existing buildings that we still recognize assimilated the introduction of water networks and wastewater disposal, electricity and artificial lighting, new people and new uses. It is now time to help these buildings to embrace the XXI century revolution of smart cities while keeping our visible memory alive.
\end{abstract}

Keywords: [building "upgrade" or retrofit, energy policies]

\footnotetext{
${ }^{\mathrm{a}}$ E-mail: info@modular.pt

${ }^{\mathrm{b}}$ E-mail: manuel.gameiro@dem.uc.pt
}

This is an Open Access article distributed under the terms of the Creative Commons Attribution License 2.0, which permits unrestricted use, distribution, and reproduction in any medium, provided the original work is properly cited. 


\section{Context}

When looking to its own city centre, the observer experiences a mirrored sensation: the regularly recognized image builds itself a sense of immutability, where each new mark grows from the surprise of a wound to the acceptance of a scar, and where a longer look brings memories of previously halted moments, superimposed to the reality using past references as aligning points.

Cities evolve and adapt, slowly fighting, following and incorporating the needs of each generation, constraining while protecting: (slow) time sprays the "foam" from innovation, increasing adherence and, again, the inertia we tend to recognize and value. City centres were, are and will (probably) be crossroads of people, information and goods, as well as references for those who live, trade or hearsay about them, intertwining economic, physical or quantitative approaches with irregular parameters as uses, local constraints, appropriateness or notions of beauty.

As mediators between interior and exterior, buildings control flows of energy and matter allowing, denying or moderating conflicting needs. But the buildings interact with the people that inhabit them and, with their real or virtual presence, give the existing shell a meaning and energy needs. This close relation with the inhabitants, with their varied/variable habits and wide local, social and geographic contexts compromises the existence of a globally adequate building.

To tackle this diversity the proposal to "upgrade" includes the notion of a phased improvement of what we "have and know" to something we "want and expect", an opportunity that can be used, or not, to intervene in the "historical" city centres, places of our collective memory. It assumes that the solutions designed for new buildings cannot be directly transferred to the existing ones, and that empowering the consumer with basic energy efficiency skills and sustainability knowledge is essential to promote collective involvement on the needed changes: "prosumers", as individuals or companies, will act on multi-criteria choices and dynamic equilibrium, adopting innovation, reporting back successes and incompatibilities, speeding up the product-to-market times and validating good choices.

Having in mind that a solution for existing buildings is only viable in a "mass-customized" individual context, this text remembers some of the basic problems, and possible directions.

\subsection{Is the building user a consumer?}

The impact of the buildings sector in the European Community energy consumption is emphasized in the EPBD-recast proposal:

"The sector has significant untapped potential for cost-effective energy savings which, if realized, would mean that in 2020 the EU will consume 11\% less final energy." [1]

In the same Directive the need to preserve the welfare of the European citizens, the importance of new markets creation and the adequacy to the climate change objectives include a warning:

"the population is not always aware of their role and added value. If this is not understood

and they are treated just as an additional administrative requirement, the potential positive impact will not be realized." [1]

The assumption of the consumer as the final user, and as such unable to defend his own rights against the powerful companies, has been long consecrated in the European legislation, enforcing the need to "protect the health, safety and economic interests of consumers and to provide adequate information" [3] , further enhanced in 1975 on a "preliminary programme of the European Economic Community for a consumer protection and information policy" [4] and later "promoting their right to information, education and to organize themselves in order to safeguard their interests" [5]. An important impulse to this process was the Aarhus Convention [6] that was later included on the Directive 2005/370/EC, "on the conclusion, on behalf of the European Community, of an amendment to the Convention on access to information, public participation in decision making and access to justice in environmental matters" [7], a document that entitled the consumers a recognized role as an important stakeholder. Conceptually the consumers evolved from victims to partners watching against the abuses of the big companies or states.

The need to communicate energy efficient measures and the importance of consumers as multiplication factors of good practices is stated in relevant documents as the Directive 2005/32/EC, 
"establishing a framework for the setting of ecodesign requirements" [8] for energy-using products (EuP), a document that included the consumers in their own protection through the obligation of providing manuals and specifications in some of the languages of the countries where the product is sold, although the reading-ability is not a guarantee of understanding:

"1. Before an EuP covered by implementing measures is placed on the market and/or put into service, a CE conformity marking shall be affixed and a declaration of conformity issued whereby the manufacturer or its authorised representative ensures and declares that the EuP complies with all relevant provisions of the applicable implementing measure. (p.29) [8]

In the same Directive the article 14 indicates the manufacturers as responsible for consumer information:

"In accordance with the applicable implementing measure manufacturers shall ensure, in the

form they deem appropriate, that consumers of EuPs are provided with:

-- the requisite information on the role that they can play in the sustainable use of the product;

-- when required by the implementing measures, the ecological profile of the product and the benefits of ecodesign.” .(p.39) [8]

On the practical side this outstanding legislative tradition still considers the buildings we live and work in as "assets", liberated from the obligation of safety, information and efficiency, depriving the European consumers from their established rights and guarantees. By entitling building users as consumers we recognize their lawful rights, briefly stated above, and recognize buildings, and their fractions, as products and services, forced to comply, and maintain compliance, with basic safety and health regulations.

\subsection{Assimilated evolution in buildings}

Cities observed and participated in the introduction of more or less intrusive innovations in their buildings. The assimilation of electricity required production areas and power reduction buildings, a profusion of cables, electrical street lighting and, inside, heating and cooling, telephone, radio and $\mathrm{TV}$, progressively protruding outside with cooling units and parabolic dishes. The assimilation of grid water required storage tanks and supply systems that pierced buildings while creating the need of "bathroom" spaces in the houses and recollection systems for used water, with its ducts or exterior draining pipes converging into treatment areas punctuated by service installations.

This increasing array of items was accompanied by a progressive change of habits that lead users to other buildings - factories, offices, schools, amongst many others -, in a process that progressively interrupted centuries of household traditions: the previously continuous use, with the fire always burning to cook, grandparents and grandsons cohabiting and high inertia walls was progressively substituted by weekdays night use and low inertia walls, and a significant change on the notions of comfort.

The buildings that we still recognize assimilated water networks and wastewater disposal, electricity and artificial lighting, new people and new uses. It is now time to help these buildings to embrace the XXI century revolution of smart cities while keeping our visible memory alive.

\subsection{The needed evolution in buildings}

The existing building stock ranges from those maintained and optimized throughout the centuries to brand new zero energy buildings that emerge as statements of a desired technological future.

A first glance to the graph in the next page, available in the documentation of the Annex 50 [9] could induce a less attentive observer to consider that an energy efficient future would pass by a stronger emphasis on new efficient buildings. A closer look suggests that the energy efficiency of the surviving pre-First War buildings is better than those built post-war, but a longer thought urges considerations about their previous uses - horse stables, palaces for demonstration purposes, workers residential areas - and some thought about the original comfort solutions and sources of energy.

The nonsense of these comparisons could be taken so far as inferring that Versailles could be a nearly zero energy building, heated by biomass boilers, unaccounted for $\mathrm{CO}_{2}$ emissions calculations, and that the eventual accountable portions of coal would surely be irrelevant when divided by the 
total heated area of the palace. But it is not nonsense to remember that even in its most glorious moments the Palace of Versailles was not kept entirely at a constant temperature of $20^{\circ} \mathrm{C}$ : this "comfort" set point is used so frequently in thermal behaviour regulations that forces users to question how "uncomfortable" they, and the generations before him, have been living before being aware of this internationally validated knowledge.

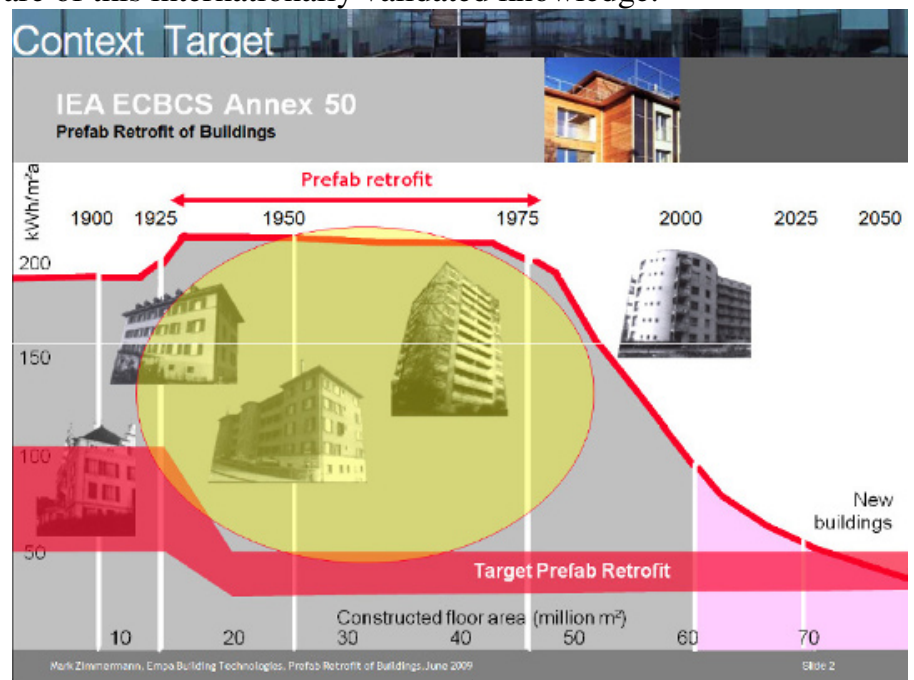

Fig. 1: Constructed floor area (milion $\left.\mathrm{m}^{2}\right)$ and associated estimated consumption [9]

Today's innovation is the need to guarantee our energy security and to reduce the human impact on climate, a goal that will require neighborhood energy services, local and regional renewable production and many other ways to spend less and better, while offering added-values like indoor ambient quality, safety and an enjoyable overall experience: change must be attractive.

\section{Identified problems}

Before adding on more empirical solutions, an effort should be made on studying the evolution of the previous (and prevailing) infrastructures and understanding, through their evolution, possible futures for the intended evolution. The fraction of the problems presented will help to understand some of the proposals, although aware that each new solution encloses two new problems.

\subsection{A technological gap}

Technology-driven products and solutions often fail massive implementation due to crossed, interdisciplinary causes like the inability to answer to the user's needs, incapacity to differentiate from existing solutions, difficulty to integrate the innovative solutions in the organizational practices and incompatibility in some specific environments:

"one credo of modern living is reductionism, the breaking down of a problem in simpler units and the belief that if we can study and understand directly this simple units, we can reassemble the whole structure in a logical fashion' [10]

The technological approaches to the energy problems have proven their inability to succeed on their own, a failure easily demonstrated by relevant architectural and technological answers to the 70 's oil crisis that never achieved scholar relevance and real day-to-day architectural practice, as Luis Fernández-Galiano comments:

"a domestic factory of energy, any prototype of an autonomous house, with its solar collectors, wind generators and methane digestors, has the appearance of a machine, is designed like a machine, and functions - though often rudimentarily - like a machine. (...) Thus, heliotechnical construction is probably the clearest expression of what could be called 'architecture of the first principle', with its emphasis on the quantitative aspects that characterize the 'culture of energy'." [11] 
Once again the oil crisis and climate change is steering the world into a stampede towards energy efficiency, but this time it's important to choose the way.

\subsection{The passive consumer}

Several comparable product specifications were designed to facilitate consumers' choice, but the technical information provided is still difficult to decode: consumers have the right to information, but the right to understand the content of that information is still not consecrated in the legislation.

An inclusive approach between technology and consumers came with the products quality certification, in which a colored scale represents the comparison between the certified product and a virtual index item. Based on technical information and scientifically determined "average" user profiles a set of parameters are defined and the products behavior evaluated within this frame: the consumer is "protected" from the information, no participation is allowed and no context is provided, creating a passive consumer that perceives Energy Efficiency as something he will (have to) buy: a paying-spectator.

The analysis of the problem and strategies available should not forget that improving the energy performance of buildings is not a factor that drives the users or owners to act [12] and that the human factor has a significant impact on spreading the desire for change.

\subsection{Legal strategies and their impact on innovation}

The importance of the legal context is frequently understated as it can promote or constrain investigation. The next paragraphs revisit common knowledge about generic types of laws and their impact on the current efforts in existing buildings upgrade, used to later identify possible approaches.

The prescriptive strategies define a set of calculation rules and constructive solutions that comply with given framework, taking for measuring purposes a virtual building "model" which represents the minimum level of energy performance. After adaptation to the reality of each place, the simplified version of the building is compared to the virtual "model", and an energy rating results from such performance comparison. The main advantage stems from the ease of compliance and verification in the situations for which the regulation was designed, and the main disadvantage derives from the difficulty of integrating diverse information as existing buildings or innovative solutions: in these cases, innovative solutions must be brought into conformity with regulations, or ignored if not recognized by managing entities, raising serious obstacles at the knowledge protection level and knowledge transference to the industry.

The modelling performance strategies are currently used in some regulations, involving the simulation of two models: the calibrated software is adjusted to comply with the regulations and study context and compared with the design team's proposals. The advantages result from the ability to integrate all the model-"able" solutions and technologies and to provide a preliminary evaluation, allowing a shift from experience based knowledge to a paradigm of virtual experimentation and multi-criteria analysis. The disadvantages result from the costs associated to the modelling process, the rare integration of the different project areas in three-dimensional databases (BIM), and the direct relation between model quality and the result: the simulation of existing buildings requires detailed representation of all mediation and control elements, making the "total simulation" unlikely in daily practice, and the results significantly different from the reality.

The "in situ"performance evaluation strategies confront designers with a threshold number or percentage to be achieved, and the project options are designed to meet or exceed this level(s) objective(s). The threshold number may be measured directly in place after the execution of works, while the evolution percentage threshold entails a preliminary assessment of the building under study, quite useful to identify the best intervention strategies [13]. The advantages range from the responsibility of the owner, designers and technicians around a common goal to the optimization possibilities that would arise from knowing the building behaviour in its context, and its real consumption. The current main disadvantages are the additional costs that compliance failures would imply, and the need to develop and test methods and equipments to evaluate the performance of the existing buildings quicker and at a lower cost. 


\section{Building upgrade: weaving the future within tradition}

The underlying concept of the ongoing Montarroio case study [13] is that although the solutions might change in each building and in each country due to varied starting points or working parameters, the equation to intertwine energy conservation, efficiency and sources with better ambient quality and use has common issues and flows: the best choice is the "instance" result, a "mass-customized" response to each set of quantitative and qualitative factors.

Assuming that we can only update that "we have and know" to achieve that "we want and expect" [13], an alternative to the current prescriptive regulatory approach is proposed: an assessment of the actual performance and a "service strategy" can significantly contribute to a measurable reduction in energy consumption, emissions and imports, and to encourage innovation.

In this paper a brief analysis of important topics towards a successful strategy is made, with the assumption that an appropriate energy efficiency policy, the desired administrative simplification and the effective accountability of designers may help override the current "conservation" interventions that mask problems, risking unhealthy air quality, safety and health, and the perceived image of a city.

\subsection{What (we want and expect)}

What we want and expect from a building derives from an existing archetype that is progressively updated to incorporate the new needs, consolidating evolution. Today's challenge to reduce fossil fuels consumption must recognize that electricity and grid water are unpaired from the notion of quantities, and that the current measurement systems are, in fact, extended reality sensors. The ongoing case study proposes the expanded use of extended reality solutions to gather information [13], to acquire knowledge and to induce user behaviours. The $\mathrm{CO}_{2}$, temperature and humidity values can provide information that, if unsatisfactory, can be crossed with external conditions, response scenarios or previous experiences to induce user interaction or automatic response. To organize the multitude of inputs this study learns from Bluyssen [14] to intertwine indoor parameters with the human response, and the Energy Service Companies approaches [15], which rely on the measurement, prediction and comparison of "shared savings", to identify complementarities capable of "making a profit".

In this perspective the analysis of the qualitative and quantitative flows that influence buildings in varied locations can be focused on their influence on users comfort and on the energetic impact of the available response options [16], disclosing adequate alternatives to each "instance" and their possible "bounce-back" effects, and opening ways towards a configurable active intervention for each existing building, and successive user.

\subsection{Who (building consumers)}

Any approach on this subject requires a look inside our own decision process: rationality is only one of the (brain) sides of the problem, where actions occur by impulse, mimics, or simple boredom. The growth of "do it yourself" (DIY) stores denounces a significant investment on "house tuning", with a significant part of such investments dedicated to bathroom and kitchen improvements, easily confirmable by the area dedicated to these themes in such comercial areas.

An evolution towards the upgrade of existing buildings must be driven by the resulting advantages, guided by regulations and boosted with incentives: the aim of a better comfort with reduced operating costs must be designed/installed by technicians that guarantee the interoperability and measurability of results, and incentives that balance the initial extra costs. In a recessing economy the existing buildings upgrade can gather the manpower surplus and the existing buildings costs reduction within midterm projects that join universities and private stakeholders.

The International Energy Agency Annex 50 [9] demonstrated that evolved methodologies can be used to capture information and assist prefabrication to optimize existing buildings intervention, while Annex 56 [2] is taking the initial steps to identify the "cost-effectiveness" and "added-value" that supports decisions. 


\section{$2^{\text {nd }}$ European Energy Conference}

\subsection{Why}

Energy Efficiency in buildings is largely dependent on users' behavior. But the term "users" is a general expression that relegates the building operators to a secondary, un-participant role. Buildings are requested, designed, approved, built, bought, operated and used by people. The analysis of the problem and strategies available should not forget that improving the energy performance of buildings is not a factor that drives the users or owners to act [12], and the human factor has a significant impact on spreading the desire for change.

The inadequacy of the statistical "average behaviour" solutions to the "particular case" struggles on the opposite side with the "Big Brother" fear associated to direct monitoring of energy use. The solution to this dilemma is only possible at the individual household scale, and such decision will only happen in an informed and inclusive context: to solve our global problem.

\subsection{How, when and where}

Given that new buildings are only about $1-2 \%$ of the total building area, recent studies show that the investment on existing buildings upgrade has lower environmental impacts [17] and a greater potential in reducing energy consumption in the medium term [13].

The option to increase the scope of current regulations to include more existing buildings can prove to be disastrous in real energy consumption and in health hazards directly related to inappropriate solutions, and impose an irreversible damage to the image of our cities.

In coherence with the previously stated concepts, no recipes are provided: each city, each historical centre, should set goals to achieve and incentives to make them happen and, learning from each other, open the way towards applied innovation.

\section{Milestone}

The problem of energy security and the impact of energy imports in the European trade balance require a long term strategy with a focus on energy consumption reduction (negenergy), efficient use of energy, a good choice of energy sources and a significant investment on renewable energies.

Knowing that innovation is a contextual process and that the upgrade of existing buildings is, in most cases, better than the investment in new buildings, uses less material and encourages greater use of local labour [17], the revitalization of historic city centres must evolve from the "must do" to "how to do". The bet on upgrading existing buildings, intertwining the recognition of pre-existence with the desired quality and comfort requirements of a "20-20-20" Europe, would also increase the attractiveness of the buildings, produce measurable reductions in direct fuel consumption/emissions and significant savings from the densification and rationalization of transports and infrastructures, without forgetting the impact on the mortality and morbidity rates [18] that reduced energy poverty and increased comfort would promote.

The high level of difficulty of the ongoing case study [13], its geometrical irregularity, contextual constraints and high efficiency goals is intended to demonstrate that it is possible to upgrade many of the simpler decaying buildings into new realities that, respecting previous tradition and knowledge, are still able to incorporate an active, efficient and comfortable future that re-attracts people to our city centers.

The regulatory gap that exists in our historic cities centres favours inertia, but this void can be used to promote freedom of action and applied innovation. The proposed "in situ" performance evaluation and existing buildings upgrade strategy for historical centres within an "applied innovation" context can contribute to the development, implementation and validation of methodologies towards an effective 20-20-20 goals achievement, while reducing the degradation problem in the historical city centres.

We have now the opportunity to demonstrate the European capacity in an internationally emerging area and to consolidate these technical and scientific solutions into demonstrable, internally applicable and externally exportable products and services. 


\section{Acknowledgments}

This project is developed within the Sustainable Energy Systems initiative of the University of Coimbra/MIT Portugal program and is funded by the SFRH/BD/51017/2010 FCT grant and developed with the engaged commitment of stakeholders from WSBP, lda (www.wsbp.eu), modular, arq:i+d, lda, IGESPAR and Câmara Municipal de Coimbra, to name a few.

The registration in the $2^{\text {nd }}$ edition of the European Energy Conference was kindly supported by the PhD scholarship offered by Mercator Stiftung (http://www.stiftung-mercator.de)

\section{References}

1. Directive 2010/31/EU of the European Parliament and of the Council of 19 May 2010 on the energy performance of buildings - accessed 2011.11.10 at http://eur-lex.europa.eu (2010).

2. IEA ECBCS. Annex 56 Energy \& Greenhouse Gas Optimised Building Renovation. Accessed in 15 de January 2012, from IEA Energy Conservation in Buildings and Community Systems: http://www.ecbcs.org/annexes/annex56.htm (2011).

3. European Union. Treaty establishing the European Community (consolidated version). Official Journal of the European Communities OJ C 321 E, 29.12.2006. (1957)

4. Council Resolution of 14.04.1975 on a preliminary programme of the European Economic Community for a consumer protection and information policy O.J. C 92 of 25.04.1975, pp. 1-16.

5. Single European Act of 17 February 1986 and 28 February 1986. Official Journal L 169, 29.6.1987, p. 1.

6. Convention on access to information, public participation in decision-making and access to justice in environmental matters. from http://www.unece.org/env/pp/documents/cep43e.pdf (accessed June 20, 2009) (1998)

7. Directive 2005/32/EC of the European Parliament and of the Council of 6 July 2005 establishing a framework for the setting of ecodesign requirements for energy-using products and amending Council Directive 92/42/EEC and Directives 96/57/EC and 2000/55/EC of the European Parliament and of the Council. Official Journal L 191, 22.07.2005, pp.29-57

8. Council Decision of 17 February 2005 on the conclusion, on behalf of the European Community, of the Convention on access to information, public participation in decision-making and access to justice in environmental matters (2005/370/EC). Official Journal L 124, (2005)

9. IEA Annex 50 - Prefabricated Systems for Low Energy Renovation of Residential Buildings, ECBCS -at http://www.ecbcs.org (accessed November 2011)

10. Williamson, T., Radford, A., \& Bennetts, H. Understanding sustainable architecture. London/New York: Spon Press (2003).

11. Fernández-Galiano, L. Fire and Memory, On architecture and Energy. Cambridge, MA: MIT Press. (1998).

12. IDEAL-EPBD. (30 de 09 de 2011). Accessed 15 de January 2012, from European Project on consumer response to energy labels in buildings, http://www.ideal-epbd.eu

13. Brito, N. S., Mateus, L. C., \& Silva, M. G. Upgrade opportunities for buildigs in city centers. Patorreb 2012. Santiago de Compostela (2012).

14. Bluyssen, P. M. - The Indoor Environment Handbook: How to make buildings healthy and comfortable, Earthscan, London (2009)

15. Limaye, D., \& Limaye, E. - Scaling up energy efficiency: the case for a Super ESCO - Energy Efficiency, 4 (2), 133-144, 10.1007/s12053-011-9119-5 (2011)

16. Vladykova, Petra, Rode, and Carten - The energy potential from the building designs differences between Europe and the Artic: proceedings of the 9th Nordic Symposium on Building Physics - NSB 2011" Tampere: Tampere University of Technology, (2011).

17. Preservation Green Lab. The Greenest Building: Quantifying the Environmental Value of Building Reuse. Seattle. from http://www.preservationnation.org/issues/sustainability/greenlab/lca/The_Greenest_Building_lowres.pdf (accessed January 2012).

18. Clinch, J. P., \& Healy, J. D. Cost-benefit analysis of domestic energy efficiency. Energy Policy 29 , pp. 113-124. (2001). 